\title{
Analysis of the USDA's 2017 Cow-Calf Management Practices Results: Part 1-Calf Crop and Calving Distribution ${ }^{1}$
}

\author{
Angela Gonella, Oscar Alejandro Ojeda-Rojas, João Bittar, and Mario Binelli²
}

Every ten years, The National Animal Health Monitoring System (NAHMS) of the United States Department of Agriculture (USDA) conducts a thorough survey to assess the management practices of the cow-calf operation throughout the country. In May of 2020, they released the results of the survey conducted in 2017: "Beef 2017: Beef Cow-Calf Management Practices in the United States, 2017" (NAHMS Beef 2020). Players in the beef industry are urged to analyze this information to measure progress and detect strengths and weaknesses in the system. Furthermore, the data reported give indication of what can be improved to ensure profitability, efficiency, and animal welfare. This series of publications aims to analyze these data, select the most relevant points, and present the big picture of the US cow-calf herd practices to stakeholders (producers, Extension agents, and the general public). When data from previous surveys (1997 and 2007) were available, a comparison was conducted to evaluate technologies' adoption over time. The raw data used to write this EDIS series may be accessed through the USDA website. This series is composed of three publications that discuss the following themes: calf crop and calving distribution; breeding practices/reproductive technologies; and bull practices and breeding soundness evaluation.

\section{Introduction}

The beef industry in the United States is one of the largest and most important in the world. The US is the largest consumer of beef on the planet. Its high-quality beef is exported worldwide. Significant research and Extension efforts have been put forth to improve the beef production chain and to increase the profitability of the industry. One of the most traditional methods used by beef producers is to establish a "defined" or "controlled" calving season. This means to manage the cow herd so that all females (cows and heifers) will calve within a limited, relatively short period instead of throughout the year. Having a defined calving season is expected to facilitate the production cycle because it will allow concentrated management of a more homogeneous group of calves (dehorning, castration, branding, vaccinations, weaning) and other animal categories in the ranch (feeding, supplementation, breeding, among others). Benefits of having a defined calving season also include weaning older/heavier calves that are less stress-prone for feedlots, better control of cow re-breeding, and increased reproductive efficiency. The producer can also take advantage of more robust markets and can optimize labor commitments so that they do not interfere with other farm tasks. This publication analyzes the calfcrop and calving distribution data reported on NAHMS

1. This document is AN375, one of a series of the Department of Animal Sciences, UF/IFAS Extension. Original publication date November 2021. Visit the EDIS website at https://edis.ifas.ufl.edu for the currently supported version of this publication.

2. Angela Gonella, DVM, MSc., Ph.D., assistant professor, beef cattle reproduction, UF/IFAS North Florida Research and Education Center; Oscar Alejandro Ojeda-Rojas, DVM, MSc., Ph.D., Department of Animal Production, University of Sao Paulo, Brazil; João Bittar, DVM, MSc., Ph.D., assistant professor, beef cattle Extension, UF College of Veterinary Medicine; and Mario Binelli, MSc., Ph.D., assistant professor, beef cattle reproduction, Department of Animal Sciences; UF/IFAS Extension, Gainesville, FL 32611.

The Institute of Food and Agricultural Sciences (IFAS) is an Equal Opportunity Institution authorized to provide research, educational information and other services

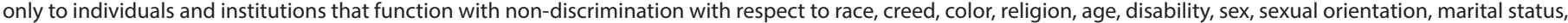
national origin, political opinions or affiliations. For more information on obtaining other UF/IFAS Extension publications, contact your county's UF/IFAS Extension office. U.S. Department of Agriculture, UF/IFAS Extension Service, University of Florida, IFAS, Florida A \& M University Cooperative Extension Program, and Boards of County Commissioners Cooperating. Nick T. Place, dean for UF/IFAS Extension. 
Beef 1997. It also compares 2017's results with the results of the USDA surveys conducted in 1997 and 2007 (NAHMS Beef 1997 and 2007). The publication provides insights and practical recommendations.

\section{Calving Season}

A defined calving season (generally around 90 days) consists of managing breeding so that calves are born during a pre-determined time interval. NAHMS Beef showed that in 2017, 55.6\% of calves were born in February, March, or April in the United States. When the result was categorized according to the operation's size, during the same period, $47.6 \%, 54.6 \%$, and $63.7 \%$ of calves were born on small, medium, or large operations, respectively (Figure 1). These data led to two conclusions: 1) even though there is a clear concentration of births in February, March, and April, there is still an important proportion of calves born out of that season, probably during months that are not favorable to their development; and 2) the calving distribution is not the same when comparing large, medium, and small producers. Large operations tend to have more concentrated calving seasons compared to small and medium operations. Additionally, data show that, in $2017,58 \%$ of the operations did not have an established breeding season. NAHMS Beef also asked the same question in the surveys conducted in 1997 and 2007. In those years, $53.6 \%$ and $54.5 \%$ of the operations reported not having an established breeding season, respectively (Figure 2). This shows that the adoption of this practice has remained stable or worsened slightly in the last 20 years.

Percentage of calves born alive in 2017 (by month born and by herd size)

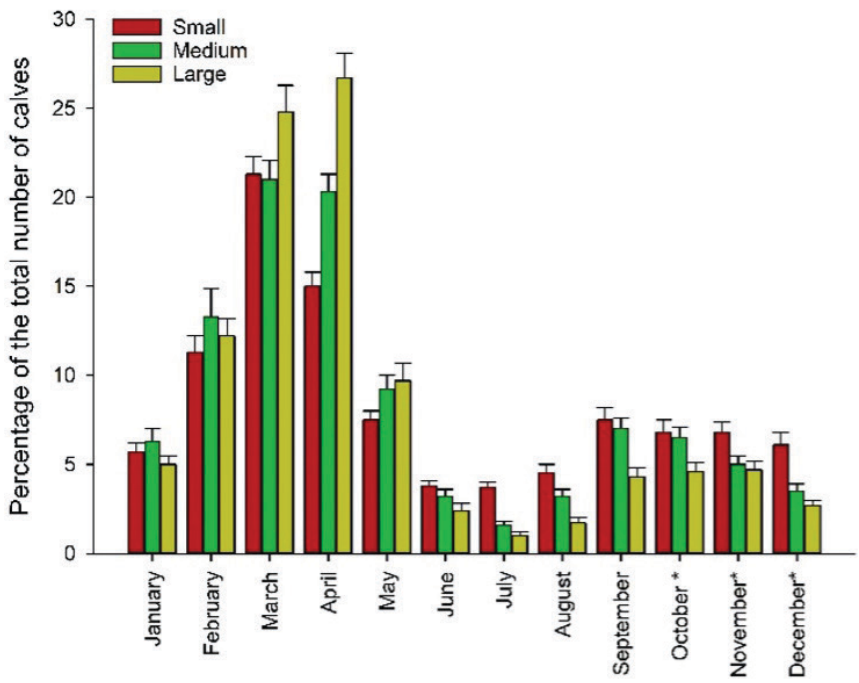

Figure 1. Percentage of calves born alive in 2017 distributed by month born and by herd size. *Indicates born alive or expected to be born alive.

Credits: Data source: NAHMS Beef 2020

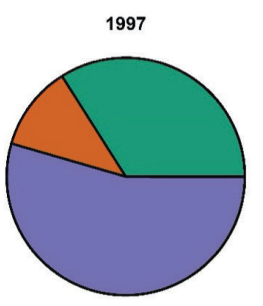

Number of calving seasons on the last two decades

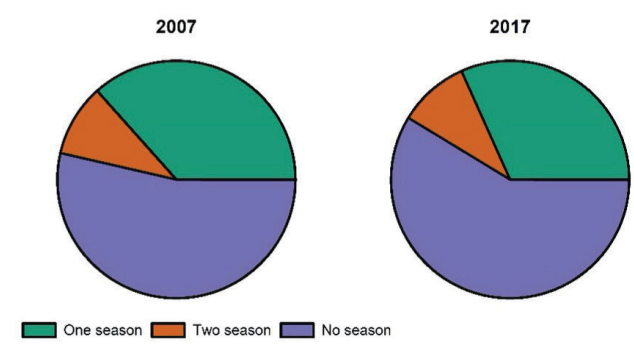

Figure 2. Percentage of operations with one or two calving seasons, or with no set calving seasons in 1997, 2007, and 2017.

Credits: Data sources: NAHMS Beef 1997, 2008, and 2020

Producers were asked to provide their opinion regarding the most critical factor that determined the timing of the last calving season (Figure 3 ). In the three surveys, "tradition" was the most important reason that influenced that decision. Although use of a calving season has proven to yield more homogeneous, heavier, and healthier calves, most of the operations continue not to have a calving season because they have been operating the same way for many years.

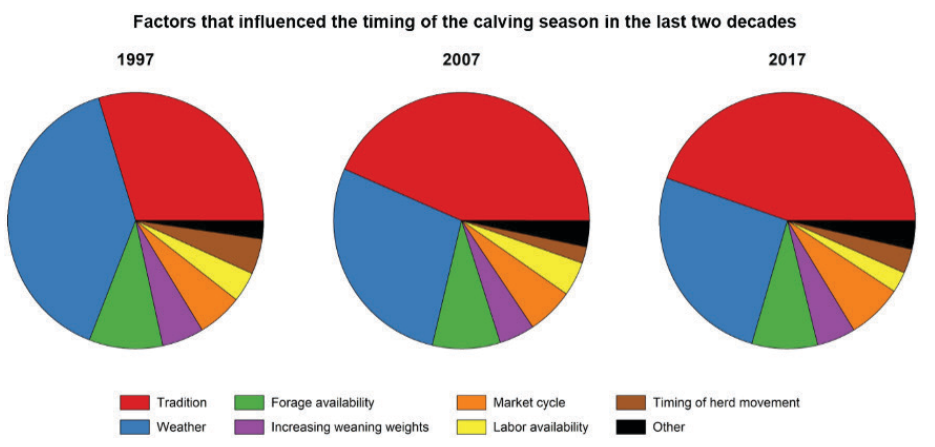

Figure 3. Factors that influenced the timing of the calving season in 1997, 2007, and 2017.

Credits: Data sources: NAHMS Beef 1997, 2008, and 2020

\section{Dehorning, Castration, and Weaning}

Some beef breeds are naturally polled, which means that they never grow horns. Nonpolled calves are usually dehorned before weaning. Dehorning is a common practice among beef cattle producers. Removing horns helps to reduce injuries to other animals and people who handle the cattle. Dehorning is a preconditioning practice that is recommended before calves enter the feedlot. It is recommended that calves are dehorned as early after birth as possible. However, due to management and labor constraints, this is not always possible. In 2017, producers were asked about the proportion of calves expected to have horns (i.e., nonpolled and not dehorned). That proportion was $7.8 \%$, regardless of operation size. Of the calves that were expected to have horns, $44.4 \%$ were expected to be dehorned. This proportion was different when comparing 
small (21.6\%), medium (43.6\%), and large (62.3\%) operations. Large operations dehorned calves at a younger average age ( 90.4 days) compared to small (162.3 days) or medium (112 days) operations (Figure 4). When comparing 2017 data with those from previous years, note that the proportion of nonpolled calves decreased significantly over the last two decades. The proportion of nonpolled calves expected to be dehorned and the age at dehorning have decreased (Figure 4).
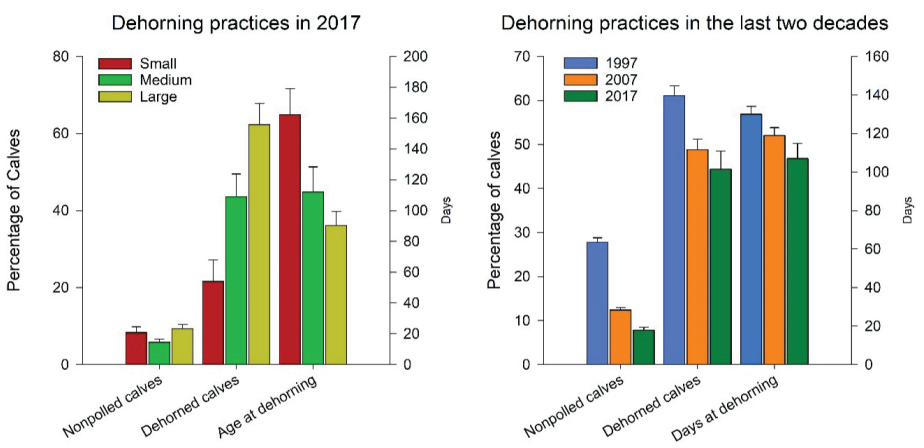

Figure 4. Left: Dehorning practices among small, medium, and large operations in 2017. Right: Dehorning practices among small, medium, and large operations in the last two decades.

Credits: Data sources: NAHMS Beef 1997, 2008, and 2020

Castration is another preconditioning practice that is commonly used before calves enter the feedlot. In commercial cattle herds, bull calves are castrated before leaving the ranch. Castration is the removal of the testes using surgical procedures or an elastrator. It is generally recommended that bull calves be castrated as early as possible, so they have enough time to heal before being shipped to the next production phase. Castration reduces testosterone levels and the associated aggressive behavior. Most of the large (90.9\%) and medium (80.5\%) operations castrated calves before selling compared with the small (55.1\%) operations (Figure 5). Overall, $62 \%$ of commercial operations in the United States castrated bull calves before selling. Age of castration was highly variable among operations: $56.7 \%$ of operations castrated their calves in the first two months of life, $19.1 \%$ of the operations did it until three months of age, and $24.2 \%$ of the operations castrated their calves after three months of age. Finally, when comparing the proportion of castrated calves in 1997, 2007, and 2017, it is evident that the overall proportion of male calves that were castrated has decreased over time (Figure 5).

On commercial cow-calf operations, calves are separated from dams and sold to a stocker or to a feed yard to continue developing. Some operations sold the calf immediately after weaning. Alternatively, operations preconditioned calves for a couple of months after weaning in order to put weight on the calves and reduce the effects of the weaning stress before selling them. A proportion of weaned heifers were kept as replacements, which means that after development, they were eventually introduced into the breeding herd. Data collected by NAHMS Beef showed that, in $2017,47.4 \%$ of the weaned calves were males, and $52.6 \%$ were heifers. Overall, $16.3 \%$ of weaned heifers were kept as replacements. This proportion was similar among the different herd sizes. During 2017, calves were weaned at an average age of 195.8 days. There were no differences in weaning age by herd size. Calves' age and weight were the most crucial factors taken into account by producers as they decided when to wean the calf crop.
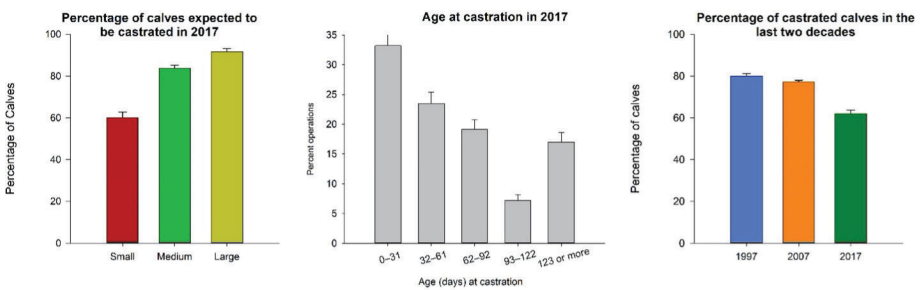

Figure 5. Left: Percentage of calves expected to be castrated in small, medium, and large operations in 2017. Center: Age at castration in 2017. Right: Percentage of calves expected to be castrated in the US in 1997, 2007, and 2017.

Credits: Data sources: NAHMS Beef 1997, 2008, and 2020

\section{Marketing Calves}

Producers were asked which strategies they used to market their calves. Simple procedures, such as administering vaccines and dewormer, dehorning, castration, and introducing calves to a feed bunk before weaning, are expected to lead to greater prices at the market. These practices are considered as part of the calf health program of an operation. The percentage of operations that provided information about their calf health programs to buyers increased as herd size increased: $35.2 \%$ of the small operations provided calf health data to buyers, compared with $59.9 \%$ of the medium operations and $78.8 \%$ of the large operations (Figure 6). Additionally, large operations tended to deliver this information in written documents more often than medium and small operations. Small operations tended to provide the information through conversations with buyers (Figure 6).

After weaning, calves were sold and sent to a feedlot, stocker operation, or cattle company. Operations providing a calf crop of perceived high quality (i.e., good sanitary status of the calves, low mortality, good genetics, and good daily gains, among others) were more likely to retain preference of particular buyers. The proportion of operations that tended to sell to the same buyer or companies each year was larger for large (78.8\%) operations than for medium (59.9\%) or small (34\%) operations (Figure 
7). Finally, producers were asked to choose from a list of specific marketing channels (i.e., certified organic, grassfed, breed-influenced program, etc.) for their beef calves. The greatest proportion of operations (59.8\%) did not target a particular marketing channel (Figure 7).

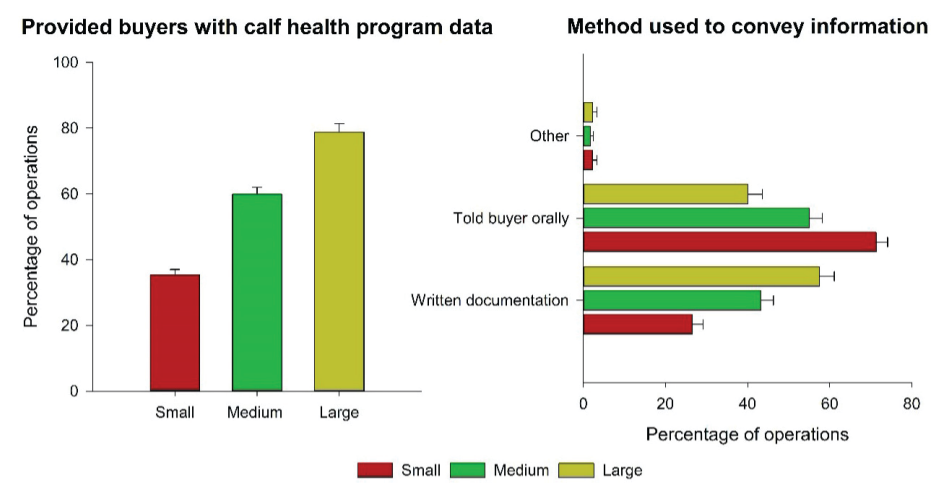

Figure 6. Left: Percentage of operations that provided buyers with information about their calf health program. Right: Method used to convey information to buyers.

Credits: Data source: NAHMS Beef 2020
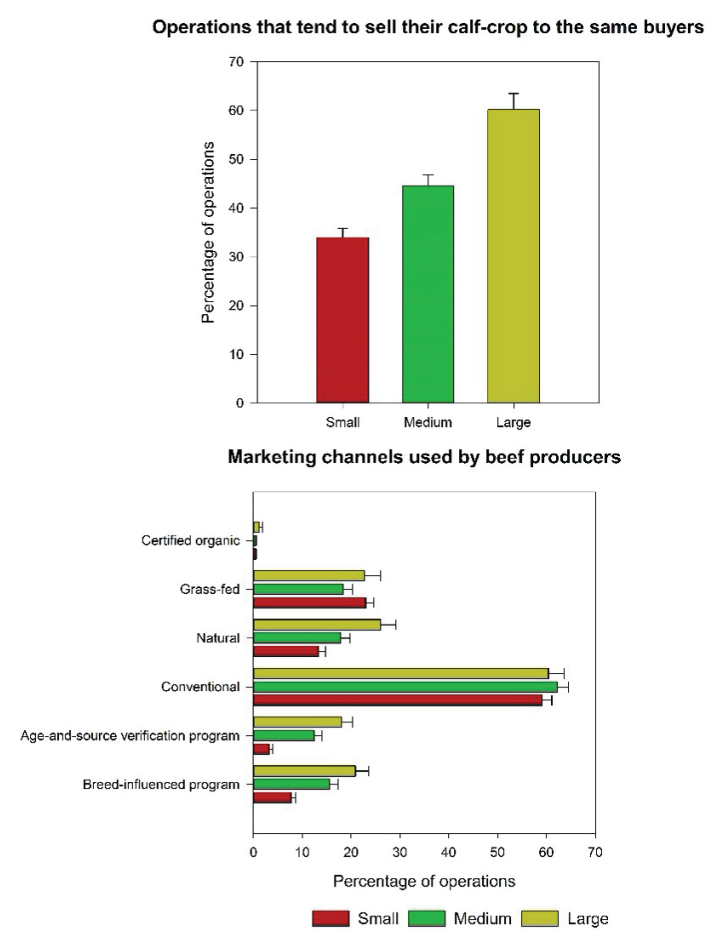

Figure 7. Top: Percentage of operations that tended to sell their calfcrop to the same buyers every year. Bottom: Marketing channels used by the operation to commercialize their calf-crop.

Credits: Data source: NAHMS Beef 2020

\section{Summary}

After the analysis of calving distribution and calf-crop data reported on NAHMS Beef 2017, the following topics need to be highlighted:

- Overall, the adoption of practices such as calving season, calf-health programs, and selling to specific market channels was more frequent in large operations than in small and medium operations.
- The adoption of practices such as dehorning, castration, and working with an established calving season has decreased over the past two decades.

- The only practice used that has increased in the last two decades is the adoption of polled breeds.

\section{Missed Opportunities}

- The opportunity to decrease labor time and expenses on the calf-cow operation: The use of an established calving season simplifies the general management of the herd by decreasing the frequency of handlings necessary for vaccinations, treatments, weaning, etc.

- The opportunity to produce more beef: Simple practices such as castration and the use of a proven calf health management program would result in healthier and heavier animals.

- The opportunity to increase profitability: Overall, beef cattle operations are generally characterized as low-profit enterprises. To reverse this situation, producers are urged to incorporate management strategies and technologies to increase efficiency and compete for more favorable market prices.

\section{References}

NAHMS. 1997. Part II: Reference of 1997 Beef Cow-Calf Health \& Health Management Practices: Beef '97. Fort Collins: United States Department of Agriculture. https:// www.aphis.usda.gov/animal_health/nahms/beefcowcalf/ downloads/beef97/Beef97_dr_PartII.pdf

NAHMS. 2008. Beef 2007-08 Part III: Changes in the U.S. Beef Cow-Calf Industry, 1993-2008. Accessed on April 8, 2013. https://www.aphis.usda.gov/animal_health/nahms/ beefcowcalf/downloads/beef0708/Beef0708_dr_PartIII_1. pdf

NAHMS. 2020. Beef 2017: Beef Cow-Calf Management Practices in the United States, 2017. Accessed on November 1, 2021. https://www.aphis.usda.gov/animal_health/nahms/ beefcowcalf/downloads/beef2017/Beef2017_dr_PartI.pdf 